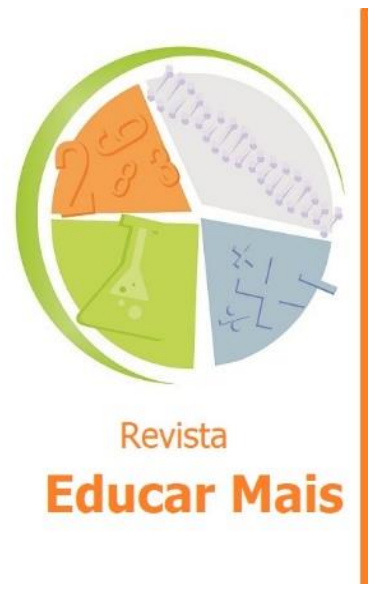

\section{O episódio histórico do centenário do eclipse de Sobral e suas implicações para o Ensino de Física por meio da divulgação científica ${ }^{1}$}

The historical episode of the centenary of the eclipse in Sobral and its implications for the Teaching of Physics through scientific divulgation

El episodio histórico del centenario del eclipse en Sobral y sus implicaciones para la Enseñanza de la Física a través de la difusión científica

Cristina Spolti Lorenzetti²; Felipe Damasio²; Anabel Raicik ${ }^{3}$

\title{
RESUMO
}

Este trabalho apresenta um sucinto resgate histórico acerca do episódio que envolveu o eclipse em Sobral e a relatividade geral; que completou 100 anos em 2019. Além disso, discorre acerca de materiais e eventos de divulgação científica oriundos da comemoração da data, promovidos pelo Instituto Federal de Santa Catarina campus Araranguá. Ainda, reflete acerca de como a divulgação científica pode contribuir para a abordagem de física moderna e contemporânea na educação científica.

Palavras-chave: Eclipse; Sobral; História da Ciência; Relatividade Geral; Divulgação Científica.

\begin{abstract}
This work presents a succinct historical rescue about the episode that involved the eclipse in Sobral and general relativity; which completed 100 years in 2019. In addition, it discusses materials and events for scientific dissemination arising from the celebration of the date, promoted by the Federal Institute of Santa Catarina Araranguá campus. It also reflects on how science communication can contribute to the approach of modern and contemporary physics in science education.
\end{abstract}

Keywords: Eclipse; Sobral; History of Science; General Relativity; Scientific Dissemination.

\section{RESUMEN}

Este trabajo presenta un sucinto rescate histórico sobre el episodio que involucró el eclipse en Sobral y la relatividad general; que completó 100 años en 2019. Además, se analizan materiales y eventos de divulgación científica derivados de la celebración de la fecha, promovida por el Instituto Federal de Santa Catarina - campus de Araranguá. También reflexiona sobre cómo la comunicación científica puede contribuir al enfoque de la física moderna y contemporánea en la educación científica.

Palabras clave: Eclipse; Sobral; Historia de la Ciencia; Relatividad General; Divulgación Científica.

\footnotetext{
${ }^{1}$ A versão inicial e resumida deste trabalho foi apresentada, em forma de pôster, no VIII Encontro Estadual de Ensino de Física/RS.

2 IFSC - Instituto Federal de Santa Catarina, Araranguá /SC - Brasil.

3 UFSC - Universidade Federal de Santa Catarina / Programa de Pós-Graduação em Educação Científica e Tecnológica (Egressa), Florianópolis/SC - Brasil.
} 


\section{INTRODUÇÃO}

Nas últimas décadas, a literatura vem enfatizando que o ensino continua expositivo tradicional, fomentando uma aprendizagem mecânica de conteúdos descontextualizados historicamente e, também, desprovidos da realidade e experiências dos estudantes (Moreira e Massoni, 2016). A Física Moderna e Contemporânea (FMC), por exemplo, não tem tido espaço nas aulas de física no ensino médio, por mais intrínseca que esteja no cotidiano da sociedade (Siqueira et al., 2018). Os próprios cursos de licenciatura, normalmente, tratam os poucos conteúdos relativos à FMC de forma mecânica, contribuindo tanto para desatualização no currículo quanto para uma formação limitada de futuros professores; que acabam não recebendo uma adequada orientação didática nesse sentido. Consequentemente, no que tange este último aspecto, formam-se docentes despreparados para tratar FMC na educação básica (Moreira, 2017).

A abordagem de FMC, na escola, mas não somente nela, torna-se ainda mais indispensável para a formação de um cidadão crítico, capaz de atuar no ambiente em que vive, pois assuntos científicos são tratados frequentemente na mídia e permeiam, por certo, discussões políticas sobre a ciência (Assunção e Nascimento, 2019). Além disso, pode tornar mais significativo o aprendizado de conteúdos de física, já que permite representar o elo entre a ciência vista na escola e o cotidiano do aluno (Monteiro, Nardi e Filho, 2012).

Um elemento que tem se mostrado útil no ensino de física, em espaços formais e não formais, é a divulgação científica (DC). Vista como um meio de democratização do conhecimento, a divulgação científica pode ser usada como forma de descentralizar as aulas de livros didáticos, promover reflexões acerca de ciência na sala de aula e para além dela e, também, auxiliar na alfabetização científica de estudantes e público em geral (Silveira e Sandrini, 2014).

O certo é que o ensino de ciências da natureza, em particular o de física, necessita de menos treinamento científico e, deveras, mais educação científica. Como destacam Damasio e Peduzzi (2016), um treinamento científico está focado em um fazer ciência, pura e simplesmente, a partir de equipamentos laboratoriais e teorias científicas, sem grandes preocupações de criticidade ou de uma aprendizagem significativa sobre a ciência. Não obstante, uma educação científica se volta (ou deveria) à significação da ciência, e nessa perspectiva, estimula-se, o desenvolvimento de abordagens históricas, filosóficas, epistemológicas etc. Estas últimas abrem caminho para a reflexão da ciência como um empreendimento humano, portanto falível e inacabado.

No que diz respeito, então, especificamente à História e Filosofia da ciência no ensino, há tempos pesquisas vêm evidenciando que o seu uso didático pode: dinamizar as aulas, contextualizar a evolução do pensamento científico, auxiliar na compreensão de teorias e conceitos científicos, desmistificar a visão estabelecida de um método científico (único e infalível), evidenciar a não neutralidade da ciência; mostrando as relações dialéticas da ciência com a sociedade, a cultura, a arte, etc. (Damasio e Peduzzi, 2016; Peduzzi, 2001; Matthews, 1995; Jorge, 2018). Com efeito, temas relativos à FMC podem subsidiar discussões nesse sentido e propiciar - quando alinhados a referenciais educacionais - a elaboração de materiais potencialmente significativos de divulgação científica.

Uma temática que, além de instigante, envolve uma figura icônica e uma história espetacular da ciência e do Brasil, é o famoso eclipse de Sobral, que comemorou seu centenário em 2019. O episódio ficou notável na história da ciência ao confirmar uma das mais importantes previsões da Teoria Geral 
da Relatividade, aquela que afirmava a existência de desvio na trajetória de raios luminosos (Videira, 2005).

Nesse sentido, este artigo salienta a relevância e interlocução que pode ser promovida entre episódios de FMC com seu resgate a partir da História e Filosofia da ciência e a divulgação científica a partir de um breve resgate histórico do Elipse Solar de Sobral; peça chave para a corroboração da Teoria Geral da Relatividade de Albert Einstein. Além disso, elucida sucintamente, uma série de atividades desenvolvidas em um Instituto Federal de Santa Catarina, articuladas à divulgação científica dessa temática, a partir da produção de um material de divulgação científica e sua difusão por diferentes meios de contato com o público.

\section{O ECLIPSE DE SOBRAL: UM SUCINTO RESGATE HISTÓRICO}

Após o desenvolvimento da Teoria da Relatividade Restrita (TRR), o físico alemão Albert Einstein (1879-1955) começou a trabalhar em incoerências teóricas que essa teoria havia deixado. Uma delas é que a gravitação newtoniana não era compatível com o sistema de referenciais da TRR (Peduzzi, 2015). Depois de 1905 - conhecido como ano miraculoso de Einstein em razão da publicação de cinco trabalhos relevantes, sendo um deles a TRR - o cientista publicou alguns trabalhos relacionados com o entendimento da gravidade.

Em 1907 Einstein publicou um trabalho - Über das Relativitätsprinzip und die aus demselben gezogenen Folgerungen' - no qual ele busca uma resposta para a questão da propagação da luz sobre influência da gravitação. Em 1911, o físico publica um novo trabalho onde ele estabelece uma nova relação da propagação da luz nas mesmas condições anteriores e sugere uma forma de testar a sua teoria (Einstein, 1911). Utilizando o princípio de Huygens - que basicamente diz que a luz que se propaga por um campo gravitacional é defletida - Einstein chega a um valor de deflexão de 0,8 segundo de arco, para a luz de estrelas que passassem pelo campo gravitacional do Sol. Para que isso pudesse ser testado Einstein (1911) sugere que "como estrelas fixas nas partes do céu perto do Sol ficam visíveis durante um eclipse total do Sol, essa consequência da teoria pode ser comparada com a experiência" (p. 908), ou seja, ele sugere a observação e registro de um eclipse solar total.

A partir disso, astrônomos de diversos países começaram a procurar meios de realizar esse experimento. Erwin Freundlich, depois de ter entrado em contado com as ideias da publicação de Einstein de 1911, procurou em registros de eclipses passados a deflexão, entretanto como tais registros não foram feitos com esse objetivo, não eram adequados para a análise (Peduzzi, 2015). Em 1912, uma expedição argentina veio para a cidade mineira de Cristina, a qual seria, em princípio, um ótimo local para realizar registros do eclipse total que aconteceria; o mau tempo não contribui com o objetivo. Em 1914, Freundlish - incentivado, inclusive financeiramente, por Einstein - se dirige à Rússia para registrar um eclipse solar. Todavia a Primeira Guerra Mundial já havia começado os telescópios e demais instrumentos astrográficos foram apreendidos, por terem sido confundidos com material bélico (Videira, 2005). Em 1916, na Venezuela, aconteceria um eclipse solar nas condições ideais para realizar os registros, nesta ocasião a expedição argentina, já citada, iria até o país. Porém, os equipamentos que foram apreendidos na Rússia dois anos antes, eram os aparelhos argentinos que haviam sido emprestados a Freundlish, impossibilitando assim a observação (Videira, 2005; Peduzzi, 2015). 
Essa sequência de acontecimentos parece ter retardado o "triunfo" de Einstein. Todavia, pode-se dizer, que não faltou "sorte" ao físico, com esses registros inconclusivos ou impedidos de serem realizados (Kennefick, 2009). Isso porque a taxa de deflexão da luz das estrelas ao passar pelo campo gravitacional do Sol estava incorreta, até novembro de 1915, quando ele apresentou à seção de física e matemática da Academia Prussiana de Ciências a teoria da relatividade geral (Pais, 1995), publicando-a no ano seguinte (Kennefick, 2009). No início de 1916, Einstein escreveu a Lorentz dizendo: "No outono passado, passei horas difíceis, ao compreender gradualmente como eram incorretas as velhas equações gravitacionais" (Pais, 1995, p. 294). Entretanto, existe um grande debate entre os físicos e os historiadores da ciência quanto a prioridade sobre as equações de campo obtidas em 1915. A ciência é um empreendimento coletivo, e o que é pouco conhecido, sobretudo no ensino, é que outros estudiosos da época também estavam em busca das equações de campo para a tal teoria (Winterberg, 2004). O matemático alemão David Hilbert (1862-1943) é um exemplo disso.

Hilbert teria chegado aos resultados cerca de cinco dias antes que o físico alemão. Winterberg (2004) discutiu a partir das fontes originais e das datas de publicação dos trabalhos sobre quem poderia ter chegado primeiro a tais equações. Einstein, em novembro de 1915 (nos dias 4 e 11), realizou duas apresentações de suas teorias na Academia Prussiana, com as equações de campo ainda incorretas; no dia 18 de novembro, o físico recebe de Hilbert uma cópia adiantada de seus trabalhos que ele apresentaria na Academia em Gottingen dois dias depois. Einstein, no entanto, respondeu a Hilbert que ele já havia chegado há algumas semanas nos mesmos resultados que ele. O curioso é que apenas uma semana antes de receber os trabalhos de Hilbert, Einstein havia apresentado uma versão incorreta de suas equações. No dia 20 de novembro de 1915 Hilbert apresenta seu trabalho à Academia, novamente, algo curioso, é o fato de que seu trabalho armazenado nos registros da Academia de Gottingen possuem cerca de um terço de página violado (página 8), alguém retirou essa parte de seu trabalho e o que segue na escrita, leva a entender que o que estava nesse um terço página eram equações de campo.

A partir do que foi exposto não é possível julgar qual dos dois teóricos teve mais relevância para a construção das equações de campo, pelas datas pode-se concluir que Hilbert não copiou as equações do trabalho apresentado por Einstein, mas também não se pode dizer que Einstein copiou as equações de Hilbert, pois existe a possibilidade de que o físico naquela semana - entre a sua apresentação à academia e o recebimento do trabalho de Hilbert - tenha chegado de maneira independente as equações corretas (Winterberg, 2004). O principal ponto que se pode chegar ao analisar essa questão é concluir que a ciência não é feita por um gênio isolado, ela é coletiva e descobertas simultâneas são possíveis. Como coloca Pais (1995):

Não pode haver uma questão de prioridade, visto que os dois autores seguiam duas vias de pensamento inteiramente diferentes (...). O tom de correspondência que se seguiu entre eles é amigável. Em maio de 1916, Einstein proferiu uma conferência sobre o trabalho de Hilbert em Berlim (p. 307-308).

Com as equações de campo já corretas, o resultado de 1911 - de 0,8 segundo de arco - recebeu um adicional em razão da curvatura do espaço-tempo em torno do Sol como previa a teoria. Com isso o novo valor de deflexão para a luz das estrelas que passavam próximas ao campo gravitacional do Sol é de 1,75 segundo de arco (Kennefick, 2009). A mencionada curvatura e o aumento da deflexão se dão pela geometria do continuum do espaço-tempo que não é euclidiana como se imaginava, o 
próprio desenvolvimento da Teoria Geral da Relatividade demandou que Einstein aprendesse a matemática dessa geometria encontrada em regiões curvas (Peduzzi, 2015).

Depois do aumento da deflexão outras expedições foram montadas para tentar corroborar com as teorias de Einstein. Em 1918, ocorreu nos Estados Unidos um eclipse solar que conseguiu ser registrado por um grupo de astrônomos, contudo os dados obtidos foram inconclusivos (Peduzzi, 2015). É importante lembrar que no período entre 1914 e 1918 acontecia a Primeira Guerra Mundial, tal contexto é importante para a discussão dos próximos acontecimentos.

Em 1916, com a Europa dividida pela Guerra, Willen de Sitter faz chegar a Inglaterra uma cópia dos trabalhos de Einstein (Inglaterra e Alemanha eram nações inimigas), e também envia uma carta ao astrônomo Arthur Eddington, falando sobre a Teoria Geral da Relatividade (Stanley, 2003). Eddington realiza grandes esforços junto ao astrônomo real Frank Dyson para que os astrônomos ingleses realizassem expedições para tentar corroborar a teoria de Einstein, a essa altura a carta de Henrique Morize já havia chegado a Inglaterra (Videira, 2005). Henrique Morize, então diretor do Observatório Nacional Brasileiro, ao saber dos trabalhos de Einstein e também das expedições realizadas por astrônomos, enviou cartas aos principais observatórios no mundo comentando acerca de eclipse solar que aconteceria em 29 de maio de 1919, nas quais ressaltou as boas condições de observação no Brasil (Crispino e Kennefick, 2019).

Foi montada então uma comissão para decidir os preparativos para as expedições - decidiu-se por dois locais de observação: Sobral, cidade do nordeste brasileiro e Príncipe, ilha localizada na costa africana - e Eddington adiantava três hipóteses de observação: (i) não observariam deflexão da luz e os conhecimentos acerca da luz teriam que ser revistos; (ii) a deflexão seria de 0,8 segundo de arco o que corroboraria com os cálculos feitos a partir da teoria newtoniana (o que eram também os primeiros cálculos feitos por Einstein); (iii) a deflexão seria de 1,75 segundo de arco, o que seria uma confirmação das previsões de Einstein para a Teoria Geral da Relatividade (Crispino e Kennefick, 2019).

Seguiram para o Brasil os ingleses Andrew Crommelin e Charles Davidson, e para a ilha de Príncipe foram Eddington e Edwin Cottingham (Crispino e Kennefick, 2019). Uma das principais preocupações que os astrônomos tinham para o dia 29 de maio de 1919, era a condição climática. Ambos os locais de observação amanheceram entre nuvens e chegaram a apresentar chuva em alguns momentos; em Sobral no instante em que acontecia o eclipse as nuvens se dissiparam e os registros puderam ser realizados; já em Príncipe ao longo das fases do eclipse ora ficava nublado ora podia-se observar o Sol eclipsado (Kennefick, 2009).

Os registros feitos em Sobral em partes foram bem aproveitados e se mostram adequados para análise posterior, contudo as fotografias feitas com o principal equipamento astrográfico que possuía um amplo campo de visão, foram descartadas por mostrarem um desvio não adequado (Videira, 2005). Esse descarte das fotografias ainda gera muitas discussões acerca da seleção (com viés) das fotografias que seriam analisadas, pois geralmente atribui-se a Eddington o descarte, assim como atribui-se a ele também uma grande preferência pelas teorias de Einstein. Entretanto as anotações feitas por Davidson apontavam perda de foco do equipamento durante a observação por conta de mudanças na temperatura do ambiente. Pode-se dizer que os registros foram realmente selecionados e a expectativa pela corroboração pode ter influenciado na escolha, entretanto o equipamento, pelo qual alguns registros foram ignorados, apresentaram irregularidades durante a observação (Crispino e Kennefick, 2019). Em Príncipe, por decorrência da presença de nuvens durante a observação, a luz 
do campo de estrelas em torno do Sol foi muito atenuada, com isso as melhores fotografias para a análise foram as registradas em Sobral com uma lente de 4 polegadas (Crispino e Kennefick, 2019). Os astrônomos permaneceram no Brasil alguns meses depois do eclipse para que pudessem realizar o registro do mesmo campo de estrelas; só que sem a presença do Sol, isto é, durante a noite. Depois de feitas as análises, foi marcado para o dia 6 de novembro de 1919 uma reunião na Royal Societye a Royal Astronomical Society - em Burlington House, Londres - para anunciar os resultados das expedições. A reunião presidida por J. J. Thomson e apresentada por Dyson, Eddington e Daividson apontou para a corroboração da Teoria Geral da Relatividade (Crispino e Kennefick, 2019).

A essa altura a população de Londres já aguardava tal resultado pelo motivo de que Eddington promoveu a teoria de Einstein durante todo o preparativo do eclipse pela imprensa local (Videira, 2005). Isso contribui para que a fama de Einstein se alastrasse depois da corroboração. No dia do anúncio um jornal local chegou a publicar uma matéria (Figura 1) cujo título afirmava que as ideias de Newton haviam sido derrubadas e uma revolução científica ocorrido (Stanley, 2003). Como bem colocou Videira (2005), tal revolução científica foi muito bem planejada.

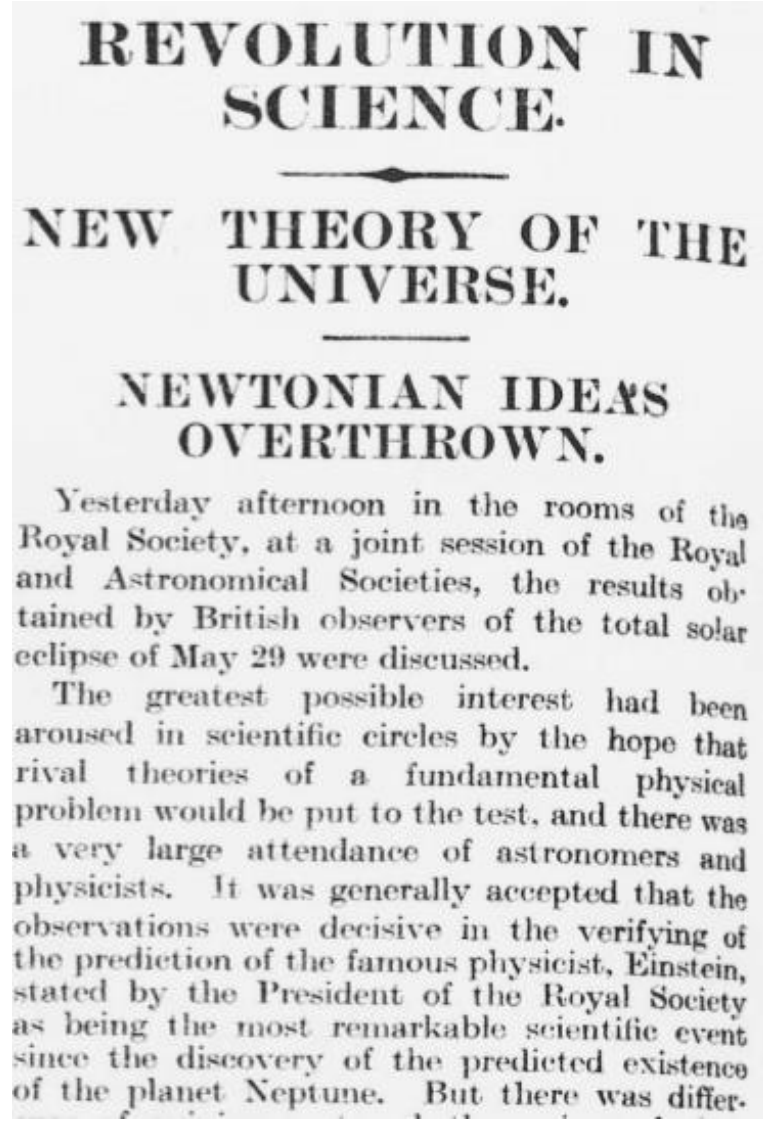

Figura 1: Jornal local de Londres no dia do anúncio da corroboração. Fonte: Stanley, 2003.

Cabe frisar que Arthur Eddington era membro da Religious Society of Friends - mais conhecida como Quaker - que pregava o pacifismo e amor ao próximo acima de qualquer coisa; é necessário dizer, correndo o risco de ser redundante, que nesse caso Eddington era um pacifista e por tanto contrário a guerra (Stanley, 2003). O astrônomo inglês via na ciência um ótimo terreno para discussões internacionais, onde o preconceito e a guerra deveriam ser contestados. Os Quaker durante a Primeira Guerra Mundial viajam para outros países, inclusive inimigos, para ajudar as pessoas que estavam sofrendo com os combates - ficando conhecidos como aventureiros - e também ajudavam seus conterrâneos a superar os horrores da Guerra (Stanley, 2003). 
Quando as ideias de Einstein chegaram até a Inglaterra por intermédio de Sitter e quando dito pela sua carta enviada a Eddington que Einstein, além de ter desenvolvido uma teoria muito interessante, era pacifista também, deixou Eddington muito animado com a ideia de que a corroboração de uma teoria de um alemão por um grupo de astrônomos inglês (nações inimigas na guerra) poderia significar muito no campo das discussões de paz (Stanley, 2003). Essa seria a "aventura" Quaker dos astrônomos ingleses.

Entretanto é importante destacar que Eddington havia feito enorme esforço para que as expedições ocorressem, mas ele mesmo não planejava participar delas. No período de guerra os astrônomos ingleses foram dispensados da convocação pela grande importância que se dava aos seus trabalhos, algo muito bom para Eddington, já que ele se recusaria a lutar na guerra por ser pacifista, o que lhe rendeira prisão (Stanley, 2003). Contudo em 1918, a Inglaterra estava necessitando fortemente de ajuda na guerra e também de mão de obra o que fez com que as dispensas dos astrônomos fossem revogadas. Para que Eddington não fosse convocado, Dyson, que tinha contatos com o almirantado, interviu e para que Eddington não fosse chamado ele teria que participar das expedições (Stanley, 2003). Foi assim que Eddington foi para Príncipe auxiliar nos registros. A sua estadia na ilha não foi uma das mais confortáveis, chovia frequentemente e a grande quantidade de mosquitos fazia com que trabalhassem debaixo de mosqueteiros. Além disso, em certa ocasião, precisou ajudar na caça de macacos que interferiam nos equipamentos (Stanley, 2003). Com tais relatos é possível observar que o empreendimento científico abriga em si incentivos vindos de diversas motivações pessoais dos cientistas. Como bem colocou Kennefick "ao interpretar resultados experimentais, contexto é tudo" (2009, p. 42).

Outro ponto a salientar é que no dia 29 de maio de 1919 não apenas a expedição inglesa esteve no Brasil, mas também uma expedição estadunidense, coordenada por Daniel Maynard Wise e Andrew Thomson. Esta viera para realizar medidas relacionadas ao magnetismo terrestre e a eletricidade da atmosfera, assim como a expedição brasileira coordenada por Henrique Morize estava presente não apenas para dar suporte aos ingleses, mas para realizar medições espectroscópicas da coroa solar (Crispino, 2018).

Após a corroboração da Teoria Geral da Relatividade, Albert Einstein ganhou notável fama. Esperavase que com a corroboração da Teoria ele recebesse o prêmio Nobel de Física. O nome de Einstein já era cotado para receber o prêmio desde 1909, entretanto componentes antissemitas no comitê do Nobel impediam a nomeação do físico (Albert Einstein era judeu). Na década de 1920 as investidas antissemitas contra ele ficaram cada vez mais fortes, Einstein foi laureado pelo prêmio referente ao ano de 1921, mas sua nomeação só foi anunciada em 1922 (Vieira, 2003). É importante ressaltar que o prêmio foi dado principalmente em razão do seu trabalho sobre o efeito fotoelétrico desenvolvido em 1905 e não pela Teoria da Relatividade Geral; o preconceito empregado contra ele era estendido aos seus estudos também. Essa questão do preconceito na ciência mostra que não apenas os estudos de certa pessoa influenciam na sua carreira científica, mas a posição que ela ocupa e as suas crenças também podem influenciar.

\section{O RESGATE HISTÓRICO DE SOBRAL E A DIVULGAÇÃO CIENTÍFICA: IMPLICAÇÕES AO ENSINO DE FMC}

Como indica Moreira (2017), o ensino de física tem se pautado, sobretudo, em uma educação mecânica; com atenção centrada no docente e acriticamente nos livros didáticos. O próprio currículo 
de física - no que tange principalmente a licenciatura, mas não se restringe a ela -, também apresenta problemas no que diz respeito às suas atualizações que, além de descontextualizados historicamente, ignoram, por exemplo, o cotidiano do aluno. Essa perspectiva, muitas vezes, cria o mito de que o desenvolvimento de conhecimento científico ocorre de maneira isolada, não propicia o entendimento da importância dos erros e a influência da sociedade nesse processo. Porém, vivemos em uma sociedade de mudanças rápidas, logo a escola e, consequentemente, os docentes precisam preparar sujeitos críticos científica e tecnologicamente (Damasio e Peduzzi, 2018). A própria ciência no século XX mostra isso, por apresentar uma grande mudança em seus modelos. Já nas primeiras décadas daquele período observa-se o "nascimento" das relatividades especial e geral e da mecânica quântica.

Um dos papeis conferidos a escola, como descrito em documentos federais de educação, é o de formar um cidadão crítico capaz de atuar no meio em que vive. Discussões relativas à FMC podem contribuir nesse sentido, visto que a carência desses conhecimentos pode tornar o estudante incapaz de discutir (ou dificultar em demasia) as decisões tomadas pelo seu governo e propiciar sua vulnerabilidade ao obscurantismo criado frente a conceitos de FMC (Assunção e Nascimento, 2019; Monteiro, Nardi e Filho, 2012; Ostermann e Moreira, 2000; Dimitriadi e Halkia, 2012).

Entretanto, como salientam Ostermann e Moreira (2001) e, também, Monteiro, Nardi e Filho (2009), os docentes saem da graduação despreparados para abordar esses assuntos em sala de aula, visto que não tiveram abordagens mínimas e adequadas de FMC, em distintos aspectos; epistemológicos, metodológicos, pedagógicos. Além disso, como apontam Ostermann e Moreira (2000) e Dimitriadi e Halkai (2012), muitas vezes se utiliza da física clássica para construir conceitos de FMC, o que acaba sendo, em alguns casos, mais um obstáculo para o processo de aprendizagem deste último. Isso, pois, essa maneira de lidar com os conceitos pode coincidir com algumas concepções alternativas que os alunos apresentam e elas, se não trabalhadas adequadamente, prejudicam uma aprendizagem significativa da ciência (Dimitriadi e Halkai, 2012).

Com isso, é possível apontar, mas não limitar, a deficiente formação de professores como um dos obstáculos para a inserção da FMC na educação básica. Muitos professores, por terem tido em sua formação um ensino dogmático e desprovidos de reflexões sobre a ciência, acabam reproduzindo esse ensino nas escolas posteriormente (Siqueira et al., 2018).

Retoma-se, então, mais uma vez a relevância de resgates históricos-filosóficos sobre temas de FMC na formação de cidadãos críticos, para que possam desenvolver a capacidade para refletir sobre ciência (Monteiro, Nardi e Filho, 2012; Hilger, 2017; Siqueira et al., 2018; Ostermann e Moreira, 2000). Nesse sentido, uma ferramenta que vem ganhando destaque é a divulgação científica. Como explicitam Silveira e Sandrini (2014), a DC tem um papel importante na democratização do conhecimento, tornando-se um importante elemento no ensino de física, tanto na educação formal quanto não formal, quando atrelada a outros referenciais teóricos alinhados e coerentes entre si. A literatura mostra que parte dos alunos da educação básica tem contato com a FMC por meio da divulgação científica (Ostermann e Moreira, 2000; Hilger, 2017), nesse contexto e a título de exemplo, como evidencia Hilger (2017) - ao valer-se da Teoria da Aprendizagem Significativa de David Ausubel para abordar a FMC - os subsunçores apresentados pelos estudantes estavam fortemente ligados à maneira com que o material de divulgação havia sido apresentado.

Por certo, resgatar questões-chave do desenvolvimento históricos da teoria geral da relatividade, por exemplo, pode propiciar discussões e reflexões acerca do papel do cientista enquanto humano, de uma ciência não dogmática, capaz de mostrar seu empreendimento, sua riqueza de detalhes e suas 
mudanças de paradigmas, etc (Peduzzi, 2001; Forato, Pietrocola e Martins, 2011). Ensinar a ciência como uma verdade absoluta é um desserviço para o cidadão que se depara com "verdades" em seu cotiado e tende a aceitá-las sem criticidade, e observa descobertas e mudanças na ciência, pela mídia, e não consegue fazer uma ligação com a ciência vista na escola, tida como acabada (Assunção e Nascimento, 2019).

Dado o exposto, e à luz do resgate histórico desenvolvido acerca do eclipse de Sobral, elaborou-se um material de divulgação científica fundamentado e coerente historicamente. Procurou-se desmistificar a ideia de que Einstein construiu sozinho a teoria da Relatividade Geral. No material, também se buscou apresentar outros acontecimentos que permearam a corroboração da teoria, que geralmente não são explorados.

O material, em si, consiste no vídeo 4 " 5 Coisas sobre a Teoria da Relatividade - 100 anos de Sobral" (Figura 2) que abordou cinco fatos que permearam o desenvolvimento e a corroboração da Relatividade Geral e que geralmente são deixados de lado. Tais acontecimentos são: (1) Se a primeira expedição montada (1914) com o intuito de observar um eclipse solar para corroborar parte das teorias de Einstein tivesse sido bem sucedida, Einstein não teria suas teorias corroboradas, pois seus cálculos sobre o desvio da luz ainda estavam incorretos; (2) Além de Einstein, outro cientista notável, David Hilbert, procurava as soluções corretas para as equações da Relatividade Geral. Inclusive existe uma inconsistência quando se fala em quem foi o primeiro a resolver as equações de maneira correta, o que se sabe é que Hilbert foi muito importante para as conclusões de Einstein e vice-versa, salientando o caráter coletivo da ciência; (3) Um dos cientistas que mais tiveram influência nas expedições que ocorreram em 1919 foi Arthur Eddington, não apenas por amor à ciência, mas também para não precisar lutar na I Guerra Mundial; (4) Algumas placas fotográficas que registraram o eclipse em 1919 foram descartadas, e eram exatamente essas placas que mais se distanciavam das teorias de Einstein. Argumenta-se então se os dados foram pré selecionados para que a Relatividade Geral fosse corroborada mais facilmente; (5) O prêmio Nobel que Einstein recebeu foi dado em virtude da sua contribuição ao estudo do efeito fotoelétrico.

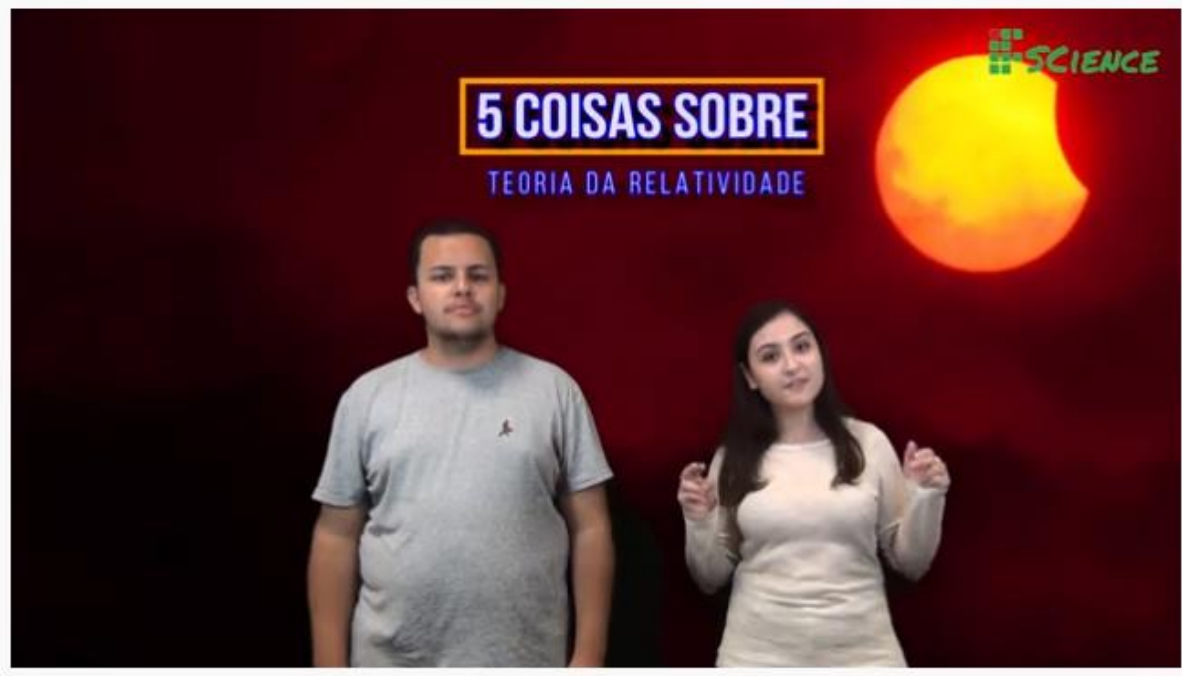

5 Coisas sobre a Teoria da Relatividade - 100 anos de Sobral

Figura 2 - vídeo acerca de curiosidades da relatividade

\footnotetext{
${ }^{4}$ Disponível em https://youtu.be/B0wLtC6OdtU
} 
Além do vídeo promoveu-se a participação de dois alunos do curso de física e um professor do IFSC, em uma entrevista concedida em um programa da rádio Araranguá (Figura 3), na cidade de mesmo nome, na data do Centenário do Eclipse de Sobral. Além de transmitida ao vivo via Facebook naquela ocasião, a "Entrevista Rádio Araranguá" encontra-se disponibilizada no canal IFScience5.

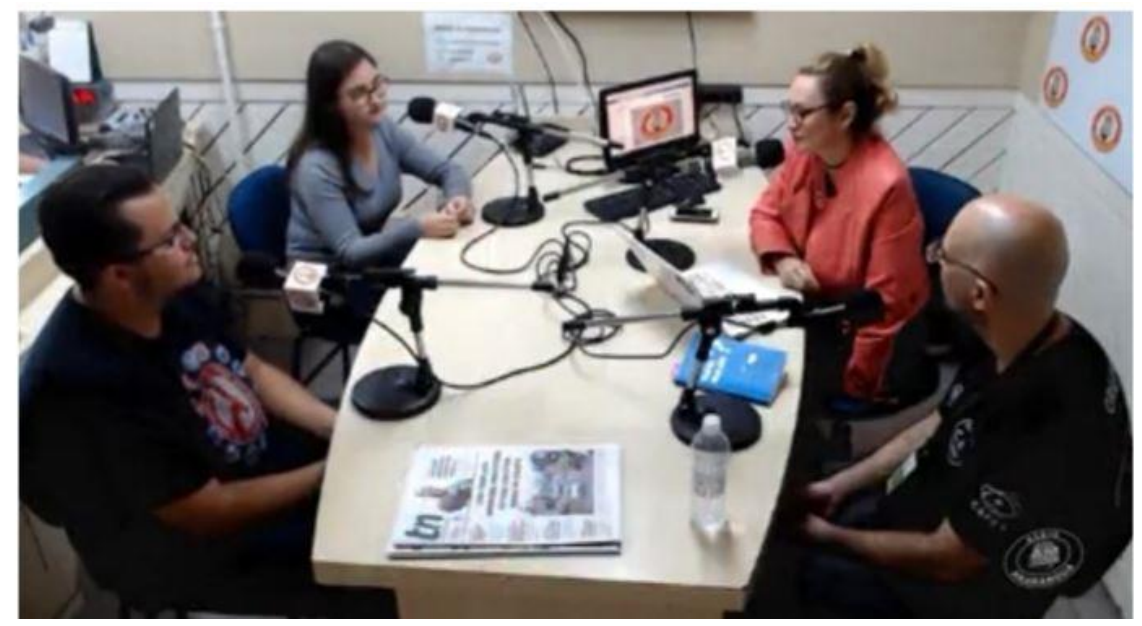

Figura 3 - entrevista de divulgação das ações em rádio local

Ademais, no primeiro semestre de 2019, realizou-se um evento aberto ao público nas dependências do IFSC, campus Araranguá, que também contou com a temática das discussões históricas acerca da corroboração da Relatividade Geral. O evento (Figuras 4 e 5) em si teve por objetivo discutir em uma abordagem histórico-fenomenológica a importância do episódio histórico de Sobral homenageando seu centenário, além de promover atividades não formais, que são profícuas para a formação dos sujeitos, muitos futuros professores do curso de Licenciatura em Física do IFSC.

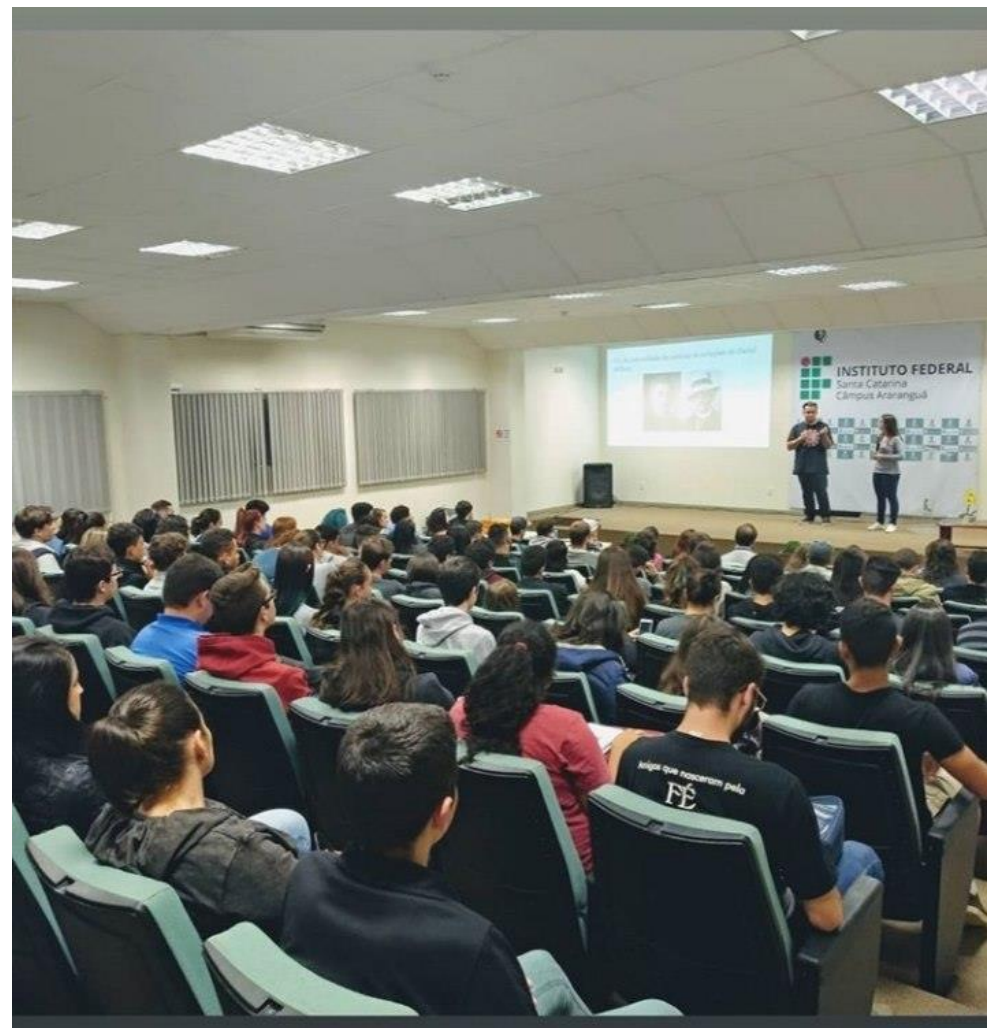

Figura 4 - palestra durante o evento de comemoração do centenário do eclipse de Sobral

${ }^{5}$ Disponível em https://youtu.be/5joKagQKdLI 


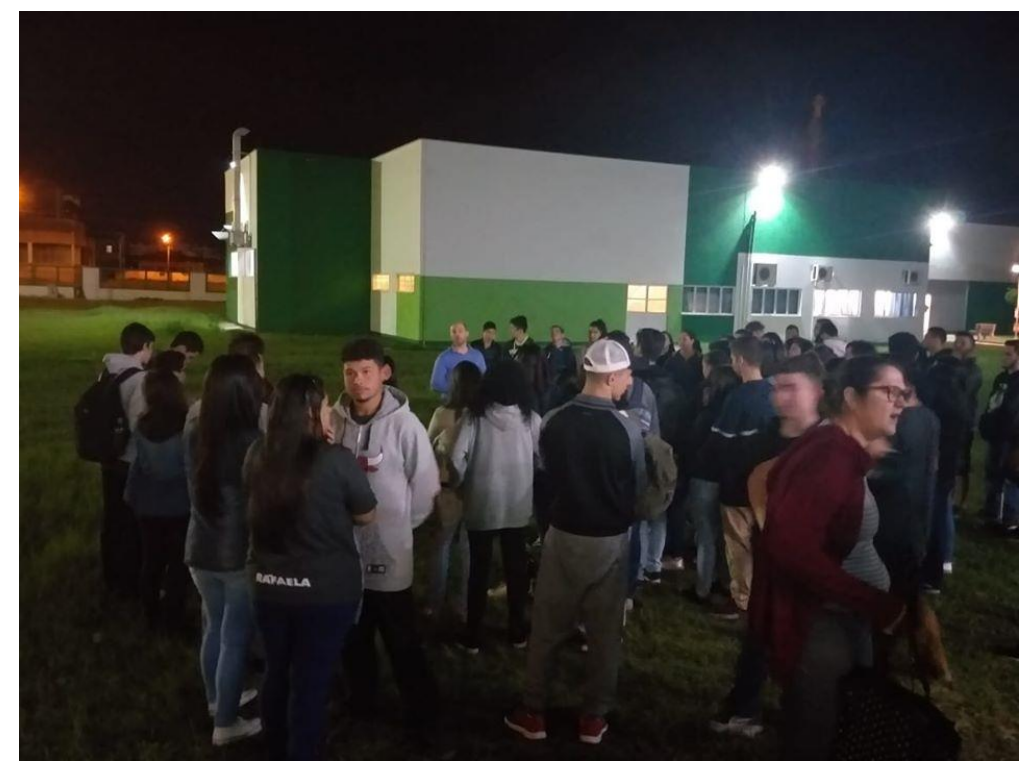

Figura 5 - atividades de observação com telescópios durante o evento

\section{CONSIDERAÇÕES FINAIS}

As atividades de divulgação científica desenvolvidas - o vídeo, a participação gravada em uma rádio local, o evento promovido no IFSC - campus Araranguá mostram seu êxito, tanto pela grande busca pelos materiais produzidos, quanto pelo público estimado que esteve presente no evento, cerca de 120 pessoas, entre professores, estudantes e público externo. É importante observar, portanto, que essas atividades propiciaram que um número considerável de pessoas, inclusive em diferentes espaços sociais, pudesse ter acesso a uma imagem mais adequada do desenvolvimento da relatividade geral; a subversão da imagem criada de que apenas Einstein a desenvolveu. Além disso, o público em geral, e estudantes da área específica, tiveram a oportunidade de reconhecer a participação do Brasil na corroboração de uma das teorias mais revolucionárias do século XX. A divulgação científica visa atingir um amplo público, não necessariamente alfabetizado cientificamente.

Não obstante, os materiais e ações de divulgação científicas elaborados, especificamente o vídeo e a entrevista, podem ser utilizados em sala de aula como forma de introdução de um conteúdo de Física Moderna e Contemporânea, através da História da Ciência, de modo a promover reflexões de e sobre ciência quando associados a outras estratégias didáticas. Materiais de divulgação científica estão, cada vez mais, sendo utilizados em atividades didáticas e, mesmo implicitamente, apresentam concepções e imagens sobre a ciência. Daí a necessidade cada vez maior da elaboração de materiais adequados, em termos históricos e epistemológicos.

Além disso, a pesquisa, produção e realização de atividades de divulgação científica ancorados em aspectos da HFC e da FMC, podem contribuir para a formação de divulgadores científicos; tanto entre graduandos, que já desenvolvem esse senso crítico, quanto de futuros docentes. Deveras, uma maior reflexão e divulgação de uma ciência adequada histórica e epistemologicamente não é prerrogativa apenas do futuro professor, mas de futuros cientistas e pesquisadores.

Ainda que não explorada no presente trabalho, uma implicação do mesmo para o ensino de física, no que tange a abordagem da Teoria da Relatividade Geral, na educação básica, nos cursos de licenciatura ou de bacharelado e na própria formação de pesquisadores, é a utilização, análise e reflexão de aspectos da Natureza da Ciência associados ao episódio (Peduzzi e Raicik, 2019). Os 
pormenores acerca da história do desenvolvimento e corroboração da Relatividade Geral envolvem, por certo, questões de ordem historiográfica, epistemológica, sociológicas, culturais da ciência.

Peduzzi e Raicik (2019) evidenciam algumas asserções relativas à Natureza da Ciência que poderiam ser explorados e relacionados ao episódio histórico aqui brevemente apresentado. Dentre as proposições, cita-se i) a influência da imaginação e não apenas do pensamento sistematizado para desenvolver as teorias - o caráter imaginativo e divagativo de Einstein, de extrema relevância para as suas teorias; ii) o papel dos dados observados, que não são neutros e "puros", mas passíveis de ambiguidades à luz das interpretações e pressupostos de quem os analisa e/ou registra - as discussões que giram em torno das interpretações das placas fotográficas que registram o eclipse de 29 de maio de 1919; iii) a compreensão de ciência como um empreendimento coletivo, não apenas no sentido de grupos de pesquisa, mas também no que se refere ao apoio de inúmeras pessoas ligadas, diretamente ou não, à pesquisa em si - nesse as colaborações (embora controversas) entre Einstein e Hilbert, assim como a ajuda que as expedições receberam da população nos locais em que foram realizadas; iv) a estrutura conceitual e epistemológica de descobertas científicas - a partir da suposta descoberta simultânea Einstein-Hilbert; v) a influência que crenças e pontos de vista pessoais, nem sempre tidos como científicos, tem no desenvolvimento de teorias ou pesquisas Eddington e os Quaker são um ótimo exemplo.

É necessário deixar claro que esses foram apenas alguns dos aspectos da Natureza da Ciência que podem ser utilizados no ensino, esse assunto é bastante complexo e amplo, digno de maior profundidade (Peduzzi e Raicik, 2019; Forato et al., 2011; Moura, 2014). A preparação conceitual de e sobre ciência que podem ser alcançadas pela História da Ciência e Natureza da Ciência, seja no ensino ou na divulgação científica, podem possibilitar um aprendizado de equações e leis com um significado concreto, ao contrário daquilo que geralmente ocorre quando simplesmente se ensina dogmaticamente. A própria análise de materiais de divulgação científica, como o filme "Einstein and Eddington" ${ }^{\prime \prime}$, podem potencializar a criticidade de estudantes em termos epistemológicos da ciência, a partir da história e da NdC.

Em síntese, e como se buscou evidenciar, tem-se necessidade da inclusão da Física Moderna e Contemporânea no ensino, entretanto pensar apenas na inclusão e não em como incluir esses assuntos não resolve a problemática. Uma perspectiva, talvez seja a interlocução entre conteúdos de FMC e a História e Filosofia da Ciência, aliados à divulgação científica, pensados para seu uso tanto em sala de aula, quanto em espaços não formais de ensino.

\section{AGRADECIMENTO}

Agradecemos ao Conselho Nacional de Desenvolvimento Científico e Tecnológico (CNPq) pelo apoio financeiro.

\footnotetext{
${ }^{6}$ Einstein and Eddington. Direção de Philip Martin. Reino Unido, 2008. (89 min).
} 


\section{REFERÊNCIAS}

ANDRADE, Rodrigo de Oliveira. O Eclipse que confirmou Einstein. Revista Fapesp, ed. 240, p. 9093, 2016.

ASSUNÇÃO, Thiago Vicente; NASCIMENTO, Robson Raabi. Alfabetização Científica e a Academia: um olhar sobre o ensino de Física Moderna e Contemporânea na Educação Básica. Revista de Ensino de Ciências e Matemática, v. 10, n. 3, p. 01-17, 2019.

CRAWFORD, Paulo. Albert Einstein: Uma biografia muito breve. Disponível em: http://rana.oal.ul.pt/ crawford/artigos/Albert\%20Einstein1b.pdf. Acesso em 19 de maio de 2020.

CRISPINO, Luís. Expeditions for the observation in Sobral, Brazil, of the May 29, 1919 total solar eclipse. International Journal of Modern Physics D, v. 27, n. 11, p. 01-10, 2018.

CRISPINO, Luís; KENNEFICK, Daniel. A hundred years of the first experimental test of general relativity. Nature Physics, v. 15, n. 5, p. 416-419, 2019.

DAMASIO, Felipe; PEDUZZI, Luiz Orlando de Quadro. A formação de professores para um ensino subversivo visando uma aprendizagem significativa crítica: uma proposta por meio de episódios históricos de ciência. Revista Labore em Ensino de Ciências, Campo Grande, v. 1, n. 1, p. 1434, 2016.

DAMASIO, Felipe; PEDUZZI, Luiz Orlando de Quadro. Para que ensinar ciência no século XXI? Reflexões a partir da filosofia de Feyerabend e do ensino subversivo para uma aprendizagem significativa crítica. Revista Ensaio Pesquisa em Educação em Ciências, Belo Horizonte, v. 20, p. 01-18, 2018.

DIMITRIADI, Kyriaki; HALKIA, Krystallia. Secondary Students' Understanding of Basic Ideas of Special Relativity. International Journal of Science Education, v. 34, n. 16, p. 2565-2582, 2012.

EINSTEIN, Albert. Über den Einfluß der Schwerkraft auf die Ausbreitung des Lichtes. Annalen der Physik, v. 340, n. 10, p. 898-908, 1911.

FORATO, Thaís Cyrino de Mello; PIETROCOLA, Maurício; MARTINS, Roberto de Andrade. Historiografia e Natureza da Ciência na sala de aula. Caderno Brasileiro de Ensino de Física, v. 28, n. 1, p. 27-59, 2011.

HILGER, Thaís Rafaela. Caminhos Possíveis de uma Pesquisa em Ensino de Física Moderna e Contemporânea até a sala de aula. Enseñanza de las Ciencias, n. extraordinário, p. 191-195, 2017.

JORGE, Letícia. Na formação de professores e cientistas, uma HQ sobre aspectos da NdC e imagens: encantar-se com os entre-(en)laces. Dissertação (Mestrado) - Programa de PósGraduação em Educação Científica e Tecnológica, Universidade Federal de Santa Catarina. Florianópolis, 2018. Recuperado de https://repositorio.ufsc.br/handle/123456789/191261.

KENNEFICK, Daniel. Testing relativity from the 1919 eclipse - a questiono $\mathrm{f}$ bias. Physics Today, v. 63 , n. 3, p. 37-42, 2009.

MATTHEWS, M. R. História, Filosofia e Ensino de Ciências: a tendência atual de reaproximação. Caderno Catarinense de Ensino de Física, v. 12, n.3, p. 164-214, 1995. https://doi.org/10.5007/\%25x.

MONTEIRO, Maria Amélia; NARDI, Roberto; FILHO, Jenner Barreto Bastos. A sistemática incompreensão da teoria quântica e as dificuldades dos professores na introdução da Física Moderna e Contemporânea no Ensino Médio. Ciência e Educação, v. 15, n. 3, p. 557-580, 2009.

MONTEIRO, Maria Amélia; NARDI, Roberto; FILHO, Jenner Barreto Bastos. Física Moderna e Contemporânea no ensino médio e a formação de professores: desencontros com a ação 
comunicativa e a ação dialógica emancipatória. Revista Electrónica de Investigación em Educación em Ciencias, v. 8, n. 1, p. 01-13, 2012.

MOREIRA, Marco Antônio. Grandes Desafios para o da Física na Educação Contemporânea. Revista do Professor de Física, Brasília, v. 1, n. 1, p. 01-13, 2017.

OSTERMANN, Fernanda; MOREIRA, Marco Antonio. Atualização do currículo de Física na escola de nível médio: um estudo dessa problemática na perspectiva de uma experiência em sala de aula e da formação inicial de professores. Caderno Catarinense de Ensino de Física, v. 18, n. 2, p. 135151, 2001.

OSTERMANN, Fernanda; MOREIRA, Marco Antonio. Uma revisão bibliográfica sobre a área de pesquisa "Física Moderna e Contemporânea no Ensino Médio". Investigação em Ensino de Ciências, v. 5, n. 1, p. 23-48, 2000.

PAIS, Abraham. Sutil É O Senhor. A Ciência E A Vida De Albert Einstein. Rio de Janeiro: Nova Fronteira, 1995.

PEDUZZI, Luiz O. Q. A relatividade einsteiniana: uma abordagem conceitual e epistemológica. Publicação Interna. Florianópolis: Departamento de Física, Universidade Federal de Santa Catarina, 2015. 259 p.

PEDUZZI, Luiz O. Q. Sobre a utilização didática da História da Ciência. In: PIETROCOLA, Maurício (Org.). Ensino de física: conteúdo, metodologia e epistemologia numa concepção integradora. Florianópolis: Editora da UFSC, 2001, p. 151-170.

PEDUZZI, Luiz O. Q.; RAICIK, Anabel Cardoso. Sobre a natureza da ciência: asserções comentadas para uma articulação com a história da ciência. Florianópolis: Universidade Federal de Santa Catarina, 2019. 57 p.

SILVEIRA, Mauro César; SANDRINI, Rafaela. Divulgação científica por meio de blogs: desafios e possibilidades para jornalistas e cientistas. Intexto, n. 31, p. 112-127, 2014.

SIQUEIRA, Maxwell et al. Obstáculos didáticos na inserção da Física Moderna e Contemporânea: um olhar a partir da formação de professores. Revista Tecné, Episteme y Didaxis, n. extraordinário, 2018.

STANLEY, Matthew. An Expedition to Heal the Wounds of War: the 1919 Eclipse and Eddington as Quaker Adventurer. Isis, v. 94, n. 1, p. 57-89, 2003.

VIDEIRA, Antonio Augusto Passos. Einstein e o eclipse de 1919. Física na Escola, v. 6, n. 1, p. 8387, 2005.

VIEIRA, Cássio Leite. Einstein: O reformulador do Universo. São Paulo: Odysseus Editora, 2003. 223 p.

VIEIRA, Cássio Leite. Pequeno Manual de Divulgação científica: dicas para cientistas e divulgadores da Ciências. Rio de Janeiro: Instituto Ciência Hoje, 2006. 48 p.

WINTERBERG, Friedwardt. On "Belated Decision in the Hilbert-Einstein Priority Dispute", published by L. Corry, J. Renn, and J. Stachel. Zeitschrift für Naturforschung A, v. 59, n. 10, p. 715-719, 2004.

' Traduzindo tem-se "Sobre o princípio da Relatividade e as conclusões dele tiradas". 